Eliciting Agents' Behaviour using Scenario-Based Questionnaire in Agent-Based Dairy Supply Chain Simulation

D.S. Utomo ${ }^{\mathrm{a}}$, B.S.S. Onggo ${ }^{\mathrm{b} *}$, S. Eldridge ${ }^{\mathrm{c}}$, A.R. Daud ${ }^{\mathrm{d}}$ and S.

Tejaningsih ${ }^{\mathrm{d}}$

${ }^{a}$ Centre for Sustainable Road Freight, Heriot Watt University, Edinburgh, UK; ${ }^{b}$ Centre for Operational Research, Management Sciences and Information Systems, University of Southampton, Southampton, UK; ${ }^{c}$ Department of Management Science, Lancaster University, Lancaster, UK; ${ }^{d}$ Faculty of Animal Husbandry, Padjadjaran University, Jatinangor, Indonesia

*corresponding author: B.S.S. Onggo, 02/4007 University Road, University of Southampton, Southampton SO17 1BJ, UK, b.s.s.onggo@soton.ac.uk 


\title{
Eliciting Agents' Behaviour using Scenario-Based Questionnaire in Agent-Based Dairy Supply Chain Simulation
}

\author{
A scenario-based questionnaire is a survey method that aims to identify the \\ respondents' decision rules using their responses to a series of scenarios. It is \\ rarely used in agent-based modelling and simulation (ABMS) with most \\ researchers preferring a survey with closed questions as the data collection \\ method. This is particularly true for ABMS studies in agri-food supply chains. In \\ our paper, we design a scenario-based questionnaire to elicit the behaviour of \\ agents in ABMS and apply it in a dairy supply chain case. Our findings suggest \\ that respondents respond well to a scenario-based questionnaire as it relates more \\ closely to their actual decision-making process. Furthermore, our experiment \\ shows that the decision rules extracted using a scenario-based questionnaire \\ improve ABMS validity.
}

Keywords: agent-based modelling and simulation; data-collection; decision rule elicitation; supply chain; dairy

\section{Introduction}

Agent-based modelling and simulation (ABMS) is an Operational Research (OR) method that has gained popularity as a decision support tool owing to its ability to relate individual behaviours to the emerging patterns of the behaviour of the system as a whole. In common with other simulation paradigms, ABMS aims to understand a problem entity. A problem entity can be something realistic (e.g., a real system or phenomenon, an ongoing policy) or something that is not happening currently (e.g., a proposed system, idea, or a planned policy) (Sargent, 2013). Depending on the type of problem entity being studied, Gilbert (2004) classifies ABMS into realistic models, which are those that aim to incorporate realistic mechanisms only, and artificial models, which are those that aim to also incorporate unreal mechanisms. The type of mechanisms modelled will, consequently, influence the ABMS development and validation techniques used. Moss (2008) classifies ABMS development and validation 
techniques into theory-driven ("theoretical") and evidence-driven ("empirical"). By empirical, we mean that the ABMS development and validation process takes into account real data (Schutte, 2010). Most artificial models are developed theoretically while a realistic ABMS can be developed theoretically, empirically, or via a combination of the two. The focus of the study in this paper is on realistic models.

The objective of our paper is to examine the usefulness of the scenario-based questionnaire, an alternative type of questionnaire survey method, in eliciting the behaviours of agents in an ABMS model. In contrast with the prevalence of the use of standard questionnaire survey (i.e., survey using close-ended questionnaire) in ABMS studies, the use of the scenario-based questionnaire is very limited. Nevertheless, in investigating respondents' beliefs, attitudes, or judgments a scenario-based questionnaire is believed to have high internal and external validity (Atzmüller and Steiner, 2010), and therefore we can expect that it can produce agents' behaviours that resemble those of the real actors. Hence, our paper contributes to the methodological research in eliciting the behaviours of agents in an ABMS model.

In order to demonstrate how the scenario-based questionnaire can be deployed, we used the example of an ABMS of a dairy supply chain in West Java, Indonesia.

Initially, we developed a baseline ABMS that was realistic using a combination of the theoretical and empirical approaches. It used the findings of previous literature (i.e., theoretical) supplemented by domain expert interviews and parameterisation of the results of a standard questionnaire survey (i.e., empirical). The aim of the ABMS was to predict the cattle and cow population and the daily milk production in the case study site. We then validated the baseline ABMS using concept of operational validity (Sargent, 2013). In parallel with this process, we derived our scenario-based questionnaire from the agents' decision rules of the baseline ABMS. Primary data 
collection was then carried out using our scenario-based questionnaire and the survey results were used to revise the agents' decision rules in our ABMS. Finally, we validated the revised models to enable a comparison between their validity and that of the baseline model.

The baseline ABMS was developed based on the theories in the previous literature and was parameterised using a standard questionnaire survey as commonly used in agricultural supply chain quantitative studies, which limits its contribution beyond that of a standard ABMS case study. However, our study provides novelty and a greater contribution in that: (i) we propose a process to design a scenario-based questionnaire from a baseline ABMS; (ii) we quantitatively show that the additional steps we propose are beneficial in producing a model with higher operational validity (more predictive); and (iii) we identify and discuss the benefits of using a scenariobased questionnaire to complement a standard questionnaire survey when developing an ABMS. To our knowledge, the use of a scenario-based questionnaire in an ABMS study is very limited, and guidelines for designing and deploying it in an ABMS study are absent.

The remainder of this paper is organised as follows. In section 2, we present the literature review to position our research in the context of behaviour elicitation method in ABMS. In section 3, we describe the dairy supply chain case that we have selected for our research. In section 4, we describe the sequence followed in order to develop a scenario-based questionnaire and the survey process. We then describe, in section 5 , the data analysis and the derivation of the elicited decision rules. In section 6 , we discuss the insights obtained from the scenario-based questionnaire survey and the simulation experiment process to test the effects of these elicited decision rules on the model validity. Finally, we end our paper with a conclusion. 


\section{Literature Review}

This section discusses the role of standard questionnaire survey in simulation studies, especially ABMS. We also discuss the drawbacks of a standard questionnaire survey and the potential of a scenario based questionnaire as a complementary approach.

\subsection{Data collection in simulation studies}

The collection and use of real-world data for ABMS development and validation is still one of the challenges facing future ABMS research (Bankes, 2002; Bruch and Atwell, 2015; Hahn, 2013; Heath, Hill, \& Ciarallo, 2009) and simulation modelling in general (Barlas, Heavey, \& Dagkakis, 2015; Onggo and Hill, 2014; Perera and Liyanage, 2000), with up to $40 \%$ of the research time being time spent on data collection (Onggo, Hill, \& Brooks, 2013; Perera and Liyanage, 2000; Trybula, 1994). There is a clear need for structured data collection methodologies in simulation (Skoogh and Johansson, 2008) and numerous data collection methodologies have been proposed to address this need (e.g. Onggo and Hill (2014), Skoogh and Johansson (2008) and Perera and Liyanage (2000)) and Barlas, et al. (2015) provide a useful review of their use. Models with higher level of detail exhibit a higher probability to cause data collection issues (Perera and Liyanage, 2000, Robinson, 1994, p. 68). This suggests that collecting and using data for ABMS models is arguably are more challenging still.

Depending on the requirements of the model, data in simulation modelling can be grouped into three types: contextual data to understand the problem situation; data for model realisation; and data for model validation (S. Robinson, 2004). In ABMS, understanding a problem situation includes an understanding as to how agents process information and make decisions. 
There are many data collection methods in simulation. In their review, Onggo and Hill (2014) identify data collection methods that have been used in simulation, including role play games, questionnaires, censuses, and historical data. Similarly, a variety of data collection methods have also been applied in the context of ABMS, including surveys with a close-ended questionnaire, case studies, stylized facts, participant observation, role-playing games, field and laboratory experiments, interviews and expert knowledge (An, 2012; Janssen and Ostrom, 2006; D. T. Robinson et al., 2007; Smajgl, Brown, Valbuena, \& Huigen, 2011; Utomo, Onggo, \& Eldridge, 2018; Yang and Gilbert, 2008). However, Utomo, et al. (2018) identify the standard questionnaire survey method is very common, especially in the field of agri-food supply chains, which encompasses the example used in this paper.

\subsection{The use of questionnaire survey data collection in simulation studies}

A standard questionnaire survey provides a quantitative method for collecting data on individuals using a series of questions, each with pre-defined sets of possible answers (closed-ended questions) (D. T. Robinson, et al., 2007; Smajgl, et al., 2011). When only a fraction of the population is sampled then it is called as sample survey (D. T. Robinson, et al., 2007). When the responses are collected from the entire population, then it is called as a census (Smajgl, et al., 2011).

The standard questionnaire survey is one of the important research methods used in ABMS (Janssen and Ostrom, 2006). A standard questionnaire survey's responses can be used to determine coefficients and constraints in an equation-based ABMS based on microeconomic theory (D. T. Robinson, et al., 2007). For example, Happe, Hutchings, Dalgaard, \& Kellerman (2011) use a farm survey to identify available resources and their potential and then create a linear optimisation matrix that describes plant and livestock production activities. Responses from a standard questionnaire survey are also 
useful in generating statistical descriptions of the agents' attributes in a population (Smajgl, et al., 2011). For example, Morgan, Brown, \& Daigneault (2015) use responses from a standard questionnaire survey to estimate the key characteristics of demographics, income, risk tolerance and current farm practices of human actors. Another use of the data from a standard survey is to construct a typology of the agents. For example, Valbuena, Verburg, \& Bregt (2008) use data concerning demographics, perceptions and farm structures from their survey to classify clusters of agents. These examples illustrate that the data obtained via a standard questionnaire survey are mainly used for model realisation purposes. Their use in understanding the problem situation and validation, particularly to elicit and validate agents' decision rules, is very limited.

However, this outcome is not without reason and a standard questionnaire survey is indeed valuable. Researchers usually design a standard questionnaire survey based on previous theories and this can effectively maintain the correspondence between existing theories and the research results (Eldabi, Irani, Paul, \& Love, 2002). This is confirmed for example by Utomo, et al. (2018) who show that, in the field of agriculture supply-chain, most ABMS that employs a standard questionnaire survey also make some references to a specific theory. This is clearly important because if the ABMS have no relationship with the previous theories at all, then its validity can be considered to be low (Jager and Janssen, 2002).

However, these advantages are not without weaknesses. Some authors suggest that sometimes a standard questionnaire survey can focus very much on theory verification and post-decision rationalisation (namely, testing whether a theory can explain a decision that has been made by real actors) (Eldabi, et al., 2002). This focus is also one of the reasons why standard questionnaire surveys predominantly use a retrospective self-report format and close-ended questions. If a process of designing a 
standard questionnaire places too much emphasis on theory verification then, sometimes, the concepts described in the questionnaire can be meaningless for the respondents (i.e., they never consider these concepts when making decisions) (Yang and Gilbert, 2008). At the same time, the close-ended questions format does not provide much opportunity for the respondents to express their point of view.

Regarding decision rules elicitation, some authors such as Janssen and Ostrom (2006) consider that responses to a standard questionnaire are prone to memory loss bias ( i.e., they are only reliable for very salient events). Others, such as D. T. Robinson, et al. (2007) consider standard questionnaire survey data as a snapshot in time. Hence, the existing conditions are captured but these are not very suitable for representing potential temporal variation (e.g., describing how the agents' decisions may change owing to changes in their environment).

For these reasons, authors, such as Smajgl, et al. (2011), consider that a standard questionnaire survey is useful for obtaining detailed descriptions of agent attributes, but they suggest the use of other methods (e.g. interviews, field experiments, role-playing games, or expert knowledge) to obtain data for understanding agent behaviour. Our study will explore if the opportunity presented by the scenario-based questionnaires, as described in the next section, can lead to reducing the drawbacks of questionnaire survey data collection while, at the same time, retaining its advantages.

\subsection{The use of scenario-based questionnaires in eliciting human decision rules}

In scientific research, scenario-based questionnaires are also known as vignette surveys. We use the term "scenario-based questionnaire" because of its common use in the supply chain research field encompassing our case study. In this survey method, a scenario is a carefully constructed illustration of a person, object, or situation which represents a systematic combination of characteristics. The wording of the scenario 
embodies the factors to be tested and is experimentally controlled by the researcher (Atzmüller and Steiner, 2010; "Encyclopedia of Survey Research Methods," 2008; Lohfeld et al., 2012).

Some authors such as Atzmüller and Steiner (2010) consider the scenario-based questionnaire as a powerful tool to elicit respondents' judgement. Consequently, researchers have applied the scenario-based questionnaire in a variety of research fields. For example, in operations management, it has been used to explore the factors influencing the decision to outsource the manufacture of a component (Mantel, Tatikonda, \& Liao, 2006). Urda and Loch (2013) use scenarios to explain how emotions and social preferences influence decision-making. Choo, Nag, \& Xia (2015) investigate how the style of executive problem solving influences knowledge accumulation and manufacturing improvement. In operational research and decision science, Azadegan, Golara, Kach, \& Mousavi (2018) use scenarios to identify the drivers for managers to increase their environmental investments. Similarly, Su, Chen, \& Ro (2017) use a scenario-based questionnaire to investigate the effects of individual negotiation styles on the opportunism and compliance behaviours of buyers and suppliers. In computer science, Jafarkarimi, Saadatdoost, Sim, \& Hee (2016), employ scenario-based questionnaires to study ethical dilemmas in using social networking sites. In the field of R\&D management, Cowlrick, Hedner, Wolf, Olausson, \& Klofsten (2011) utilise it to analyse entrepreneurial risk and attitude while there are plentiful examples from the fields of health and psychology. All these studies affirm the benefits of a scenario-based questionnaire in identifying the real actors' decision rules. However, none of these studies uses the behaviours elicited to develop an ABMS model and this highlights a clear research opportunity within the field of ABMS. 
Typically, researchers derive the scenario-based questionnaire from theoretical concepts (e.g., the theory of planned behaviour (Jafarkarimi, et al., 2016)). Using these theories, they hypothesize the relationship between a series of factors with the behaviour to be explored. Then they design the survey experiment by varying the level of each factor (Atzmüller and Steiner, 2010) with full factorial design being the most popular design of experiment. The researcher then converts each experimental set into an illustration of a problem in which the respondents must make a decision (i.e., a scenario). This step is important in that it can reduce the previously mentioned biases arising from memory loss. These scenarios require the respondents to solve a current and representative decision problem rather than try to recall a previous event (i.e., a retrospective self-report). An earlier study has highlighted that scenarios designed using real world situations allow the researcher to make generalizations or draw conclusions about an individual's or a group's behaviours in reality (Cowlrick, et al., 2011). The scenario format may also be more easily understood by respondents who do not have a technical background when compared with asking them to confirm a decision tree or flow chart.

We consider that there are similarities between the process for designing a realistic ABMS and a scenario-based questionnaire. As explained earlier, an ABMS can be developed theoretically or empirically. In principle, the initial (baseline) ABMS is a collection of mechanisms and decision rules that are hypothesized by researchers (Axelrod, 1997). The researchers then compare the ABMS's outputs with the real phenomena. If there are similarities between the two, the researcher can claim that the hypothesized mechanisms and decision rules are sufficient (though not necessarily correct) to generate the observed real phenomena (Epstein, 1999). If we combine the steps to design a scenario-based questionnaire with the ABMS then we can make a 
stronger claim as to the model's validity because we can claim that the mechanisms and decision rules that have been confirmed by respondents (rather than just hypothesized) are sufficient to generate observable macro phenomena.

Consequently, in our study, we developed the scenarios for our survey using the hypothesized decision rules created for the model (described further in Section 3) from the findings of a literature review and then created a narrative for each scenario that was adapted from the real world farmers' experience.

\section{Dairy Supply Chain in West Java and the Baseline Model}

ABMS has long been used to support policy making in the agri-food supply chain (Utomo, et al., 2018). Policy makers in Indonesia have also realized the benefits of simulation modelling in supporting policy making, including in the dairy supply chain (Sunitiyoso, Wicaksono, Utomo, Putro, \& Mangkusubroto, 2012). Currently, system dynamics is the most widely used simulation methodology by the policy makers in Indonesia (IAARD, 2012). For the dairy supply chain in particular, they have developed sophisticated system dynamics models that can predict important parameters such as milk production by considering a variety of factors such as changes in demographics and macroeconomic conditions. Our full-scale ABMS aims to complement these models by incorporating the real actors' individual behaviour. Such models will allow the policy makers to analyse the effect of real actors' behaviours on the whole system performance, and to design interventions that can encourage the real actors to adopt more preferable behaviours. The model presented hereafter is a subset of our full-scale ABMS, and focuses on farmers' decision-making rules in selling and buying cows. This is because it is not possible to describe both the full-scale model and the process to design the scenario-based questionnaire in detail in one paper. 
The typical dairy supply chain in Indonesia is composed of many tiers comprising farmers, cooperatives (collector and handler), milk processing industries (processors), retailers and consumers. In common with earlier studies, the number of farmers is large while the number of processors is very small (Glock, 2012). Most farmers are smallholders who own relatively little land, which is only sufficient to build a pen for their cattle and achieve relatively low production levels. For reasons of security, the pens are usually located next to the farmers' houses in the middle of residential areas. The forage grows along the road and riverbanks. The farmers gather the forage from outside of their village using carts or motorcycles because it is difficult for them to herd their cattle through the residential area. In this sense, forage is a common resource for all these farmers. Hence, in the situation where the forage availability is low, the competition between farmers to obtain forage should become more intense and we expect certain behaviours would emerge as described for other common resources such as fisheries (Bravo, 2011; Morano, de Moraes, \& Jacomossi, 2018). However, in our case, such an extreme scarcity has not been observed in recent years and we did not include this scenario in our questionnaire. Indeed, one of the major concerns for policy makers is declining farmer and cow populations.

In this supply chain, the milk produced by the farmers is collected and transported to the milk processors by farmers' cooperatives. The role of a farmers' cooperative is important because it is cheaper for the milk processing industries to buy milk in large quantities and, also, because it is highly perishable, the milk must be transported efficiently and refrigerated at all times (Glover, Champion, Daniels, \& Dainty, 2014; Manish and Sanjay, 2013), which is prohibitively expensive for the smallholder farmers. However, the cooperative's decisions are not fully controlled by the farmers. The cooperative also has external investors, shareholders and employs 
professional managers and workers. Hence, the cooperative operates like an independent company with smallholder farmers acting as suppliers who have little influence on the cooperative's decisions.

Consequently, we modelled a dyadic interaction between smallholder farmers and the cooperative in West Java using ABMS. The dairy supply chain in the case study area is one of the biggest in Indonesia and we considered it representative of other dairy supply chains in the country. Furthermore, we believe the case of the dairy supply chain to be suitable to demonstrate the benefits of a scenario-based questionnaire because the smallholder farmers (i.e., the respondents in our study) usually control their own decisions. Hence, the respondent's answer will correspond directly with the agent's decision rules in the simulation. This is in contrast to supply chains featuring large organisations in which the decisions are more likely to be made by a management team or via group agreement.

To develop the base model, we followed the suggestions of (Gilbert, 2004) and collated the relevant body of knowledge from previous studies. During this literature review, we found two sets of models relevant to the dairy supply chain. The first set of models (e.g., Happe, Schnicke, Sahrbacher, \& Kellermann (2009), Happe, et al. (2011), Marohn et al. (2013), Quang, Schreinemachers, \& Berger (2014)) assumes that farmers have a land endowment. They maximize their income by allocating their land to produce multiple crops. If the farmers decide to produce milk, then they allocate some of their land to grow the forage. The second set of models comprise grazing models (e.g., Gross, McAllister, Abel, Smith, \& Maru (2006), Boone et al. (2011), Martin, Linstädter, Frank, \& Müller (2016), Rasch, Heckelei, Oomen, \& Naumann (2016), Rasch, Heckelei, Storm, Oomen, \& Naumann (2017)) in which the farmers herd their livestock to a common source of forage (i.e., the rangeland). In our case study area, the 
farmers also mainly rely on their surrounding environment as a common source of forage. Thus, we considered the second set of models to be more suitable as the foundation for our base model. However, the farmers in our case need to transport forage for their cattle while the cattle do not move at all. This introduced more constraints into our modelling such as labour, working hours and transport capacity.

The focus of this paper is not to describe the base model development in detail but to demonstrate how a scenario-based questionnaire is used to elicit key farmers' decision rules to be implemented in the model. Consequently, we have summarised the mechanism used in the base model, together with the main literature we have collated to develop the base ABMS and our scenario-based questionnaire in Figure 1. A more detailed description of each mechanism and the model is provided in the supplementary materials.

Figure 1. Flowchart of the base ABMS accompanied with the main literature used to develop each module

\section{Survey Instrument Design and Survey Process}

\subsection{Process to design the survey instrument}

The purpose of our survey was the collection of data that we could use to parameterise our ABMS and elicit decision rules of the farmer agents in the model. The cooperative was excluded from the survey because its decisions are made by many decision makers collectively. Figure 2 describes the process we adopted to design our survey instrument. This figure shows that questions aim to parameterise our ABMS are grouped in Part 1 of the survey instrument, while scenarios to elicit the agents' decision rules are grouped in Part 2. 
Figure 2. Flow chart of the process to develop the survey instrument

To develop the questions in Part 1, we began by listing the parameters used in the base ABMS. These parameters included demographic (e.g., age and education), socio-economic (e.g., income and off-farm jobs) and technical factors (e.g., cattle ownership and cow productivity). The complete list of questions is given in the supplementary materials.

The main contribution of this paper is in the development of scenarios in Part 2 of our survey instrument. In this particular case, we want to elicit farmers' buying and selling decisions, which directly affect the size of the cattle and cow population. In developing our scenario-based questionnaire, we were assisted by a number of domain experts. The domain experts comprised lecturers and graduates from the Animal Husbandry Department of Padjadjaran University and an experienced farmer. They were chosen because they had experience in interacting with the farmers in the case study area.

Once we were clear about the decision rules to be elicited, the next phase was to list all the possible actions that can be taken by the farmers for each decision. The purpose of the scenarios was to elicit the decision rules so it was important that this list included not only actions that can be taken by the farmer agent in the base model, but also other actions that may be performed in the real world. We also provided an option where the respondents could explain actions that were not represented by other options.

In the third phase, we listed all parameters and information considered by the agent to select its action in the base ABMS (decision parameters). We then determined the range of decision parameter values that would be used to make variations of a scenario. It is important that the decision parameter range included all values that can occur in the simulation and the real world (i.e., collectively exhaustive). This was done to avoid bias owing to extrapolation (i.e., when a decision parameter value that occurs 
in the simulation goes beyond the range of data obtained from the respondent). If this happens then the agents' decision rules in the simulation are no longer representative of the real world actor. For example, in this study, we set the cattle mortality range in our scenario between $0 \%-100 \%$. We also used information from the domain experts' observations to establish these ranges, especially when the decision parameter distribution is a priori unknown. For example, the domain experts observed that there are farmers who start to sell their cattle when experiencing forage deficit for a week. However, they also observed that some farmers will retain their cattle for two months even though they are facing a forage deficit. Based on this information, we set the range of farmer's forecast horizon in our scenario between one week and two months. If a decision parameter proved to be significant while it was not possible to specify a collectively exhaustive range for it, then a special error message would be created to warn when its value in the simulation violates the data boundary. The corresponding run should be then excluded from further analysis because it may contain bias.

The next phase was to combine these actions and decision parameters with a story to develop each scenario. This scenario guides the respondents to choose their actions by considering the given decision parameters. In this phase, we asked the domain experts to retell real farmers' experiences that they have observed. We then used the minimum, maximum and mid value of each decision parameter range to vary one scenario into several sub-scenarios using factorial design. Presenting several scenario variants is important to identify the sensitivity of a real actor's actions toward the changes in decision parameter value.

Finally, we translated the questions in Part 1 and Part 2 into local language and terminologies. We also used traditional measurement units in all of the survey 
instrument questions to ensure that the respondents could understand all questions easily.

We then asked the domain experts to validate our survey instrument through a pilot test. There were several objectives of this pilot test. Firstly, it aimed to minimize errors and ambiguity by asking the domain experts to propose revisions to the questions or scenarios that were ambiguous or difficult to be understood. Secondly, the pilot testing aimed to ensure that respondents' behaviours were sensitive to the scenarios presented while keeping the questionnaire as short as possible. This was important because the factorial design we used initially resulted in a massive number of scenarios in the initial survey instrument design. We asked the domain experts to suggest new parameter values if they felt that respondents' behaviour might not be sensitive towards the decision parameter values presented. The domain experts could also propose new action options and decision parameters for a scenario. The proposed action would be considered in the revised survey instrument if it was mutually exclusive to the existing options and it was plausible for a real farmer. If two adjacent sub-scenarios were considered too similar and had no effect on the decision then the domain experts could propose the elimination of one of the scenarios. When changing the decision parameter values as well as eliminating a sub-scenario, it was necessary to keep the combination of decision parameter value across all sub-scenarios collectively exhausted. By using the domain experts' suggestions, we improved the survey instrument design over the course of three iterations.

\subsection{Survey and analysis process}

The full scale survey was carried out from $1^{\text {st }}$ to $31^{\text {st }}$ of August 2016. The respondents comprised 153 farmer households located in 19 villages in the West Java area. The respondents were identified from a database of the dairy cooperative members. Between 
5 and 10 respondents were taken randomly from each village. The number of respondents taken from a village depended on the proportion of the number of dairy farmers in the particular village to all cooperative's members.

The scenario-based questionnaire is generally more complex than a standard closed question questionnaire so each respondent was accompanied when completing it. This is also important to ensure that respondents can interpret the survey instrument correctly. The survey was conducted from house to house in the evening after the respondents had finished all of their daily activities to ensure there were minimal distractions for the respondents. We used hard copy format and on average, each respondent required two hours to complete all the survey questions. Randomly, we interviewed several respondents after they completed all the questions in the survey instrument. In these interviews, we asked about their perceptions regarding the survey instrument that we used. If they have participated in similar surveys (e.g., agricultural census), we also asked them to compare their experiences in responding to our scenariobased questionnaire and a standard questionnaire.

After the survey was completed, the respondent's responses were converted into an electronic format using Microsoft Excel and SPSS. Codes were used to record responses to closed answer questions in part 1 and part 2. If the respondent gave open answers, the respondent's answers were then transcribed as sentences. This transcript was then read in turn by the research team. The research team then agreed whether the respondent's answer could be classified into one of the codes used in the closed answer option.

Similarly for open answer responses, the respondent's response to interview questions was transcribed into sentences. Each transcript was read in turn by the research team. The research team then classified the respondents' response, for 
example, as to whether the respondent can easily understand the survey instrument and whether the respondent prefers the scenario-based questionnaire to the standard questionnaire.

\section{Survey Findings}

Part 1 of the questionnaire shows that our respondents are quite homogeneous. That is, $98 \%$ of them are smallholders who have 7 or less cows, $85 \%$ of them have less than 600 $\mathrm{m}^{2}$ of land, and $85 \%$ of them have been in dairy farming for less than 20 years. We also obtained the parameter values and distributions that would be used in the simulation model (Table 1).

Table 1. Simulation model parameters.

Part 2 of the questionnaire (i.e., the scenarios) is used to elicit farmers' buying and selling decisions. These decisions are important because the objective of our model is to predict the impact of these decisions on the volume of milk production and the size of the cattle and cow population.

\subsection{Buying decision rule}

Gross, et al. (2006) suggest that the farmers' willingness to buy new cows is influenced by the excess forage they obtain. Our domain experts who are mostly experts in animal husbandry, suggested that higher milk price should also be considered as it has been discussed in animal husbandry literature (e.g., Nicholson, Thornton, \& Muinga (2004)). Hence, we combined these two factors to represent the farmers' buying decision rule. This combination produced four sub-scenarios that would be used to test whether those factors were significant (Appendix, Scenario 1). In each sub-scenario, we asked the respondent to state how many cows they are willing to buy assuming that they have 
sufficient money.

We used regression analysis to estimate the number of cows that a farmer will buy based on the two factors. Owing to the high skewness in the excess forage data, we transformed it using a square root function to obtain a better fit. The regression model (equation 1) shows that the only significant predictor is the square root of additional forage obtained and it explained $14.7 \%$ of the variation in the number of cows a farmer wanted to buy. The low coefficient value indicates that the farmers are risk averse. The fact that milk price is not significant indicates that the farmers in our case study have different behaviour from what has been discussed in the previous studies related to animal husbandry. The complete statistical analysis is available from the supplementary materials. The buying decision rule that we used to revise our baseline ABMS is shown in Figure 3.

$$
A d d_{\text {Cow }}=-1.603+0.095 \text { Add_Forage }{ }^{\frac{1}{2}}
$$

\section{Figure 3. Buying decision rule}

\subsection{Selling Decision Rule}

The literature suggests that the smallholder farmers' decision to sell their cows is influenced by the forage deficit or financial problem they are experiencing (Boone, et al., 2011; Gross, et al., 2006). Our domain experts suggested that when farmers sell their cows due to forage deficit, it is mainly because of its impact on their cattle's health. The farmers obtain their cattle's health information from a veterinarian who visits them weekly. Based on this suggestion, we added the information provided by the veterinarians concerning the cattle's health condition to the scenario. The scenario is presented in the appendix (Scenario 2). 
To test the influence of information provided by the veterinarians on the probability of selling, we used logistic regression. The regression model is shown in Equation 2. The model is significant and the Nagelkerke pseudo $\mathrm{R}^{2}$ shows that the model can predict $75 \%$ of respondents' response. The coefficient shows that as the likelihood for the cow to become sick and die increases, the more the farmers choose to sell the cow. We present the complete statistical analysis result in the supplementary materials. The selling decision due to forage deficit is shown in the left flowchart on Figure 4.

$$
\ln \frac{P_{\text {sell }}}{1-P_{\text {sell }}}=11.442 P_{\text {die }}-6.342
$$

\section{Figure 4. Selling decision rules}

When farmers are forced to sell cows owing to a financial problem, the literature typically assume that farmers prioritize the sale of the oldest cows first (e.g., Boone, et al. (2011)). During the pilot testing, our domain experts proposed other factors that might be considered by the farmers, namely: cow fertility and whether it is pregnant or not. Hence, we also incorporated these factors into our scenario-based questionnaire (Appendix, Scenario 3). In each scenario, we asked the farmers to compare two cows with different characteristics. We then asked them to choose which cow they preferred to sell. From this pairwise comparison, the research team then helped the respondents to order their preference from 1 (the most preferred) to 8 (the least preferred).

We used regression analysis to describe the farmers' preference. The regression model shows that all three factors are significant predictors of farmers' preference and the model $\mathrm{R}^{2}$ is $97.8 \%$. We present the complete statistical analysis result in the supplementary materials. Equation 3 shows that age becomes the first criteria in farmer 
selection process (Young $=1$ for young cows and 0 for old cows) followed by pregnancy (NotPregnant $=1$ for not pregnant cows and 0 for pregnant cows) and fertility factors $($ Fertile $=1$ for high fertility and 0 for low fertility), respectively. The farmers place higher priority on selling a cow that is older, with low fertility, and not pregnant. The selling decision due to financial problem is shown in the right flowchart on Figure 4.

Priority $=2.77+4 *$ Young $+1.22 *$ Fertile $-1.75 *$ Not Pregnant

\section{Discussion}

\subsection{Respondents' perception toward the scenario-based questionnaire}

Our experience during the data collection shows that most of the respondents could understand the scenarios that were presented. During the data collection, there were a few respondents who found it difficult to understand the scenarios. In these instances, we asked them to express their understanding of the scenario presented. If the respondent's understanding is not much different from the scenario's intention, then we ask them to answer based on their understanding. Otherwise, we allow them to give no response to the scenario (this only happens once during our data collection).

In addition, there were also some respondents who used the open answer option. However, in our case study, we were always able to map their answer to one of the predefined options. For example, some respondents mentioned that when they could not get sufficient forage, they would look for alternatives to forage. In principle, this answer shows that they prefer to retain the cows they own. Supposing in another case study that the researcher cannot map the respondents' answer to the predefined options, we propose to apply coding techniques to the respondents' answers. Indeed, the 
applicability of the coding techniques depends on the number of respondents whose answers cannot be accommodated by the predefined options.

Most of our respondents had taken part in previous studies that used questionnaires as a data collection instrument. One example of these studies is the agricultural census conducted annually by the Indonesian Statistical Bureau. Therefore, they had enough experience and knowledge to compare the benefits of the scenariobased questionnaire that we used with the standard questionnaire. To reveal their perception toward our design compared to the design in the previous studies, we observed how our respondents react to the scenarios presented and conducted a short interview with some of them after they completed the questionnaire.

More than $80 \%$ of the interviewees felt that they could understand the scenarios presented because they were written in their daily language and terminology. According to the interviewees, this questionnaire was different to the questionnaires in the previous studies. In the previous surveys, it was difficult for them to imagine how the data would be used and how the research outcome would be beneficial for them (partly because the surveys often used technical terms and concepts that are more familiar to the academics). In contrast, some of the interviewees could guess how the data from the scenario-based questionnaire could be used to select interventions that might help them. For example, one of the interviewees said that "If the government or cooperative know that we decide to sell our cows because it is very difficult to collect sufficient forage, then they could help us to import forage from other regions". This finding shows that we can identify key decision factors (i.e. the importance of forage) during the data collection which help use devise potential policy interventions.

The respondents' perception during this interview provide the first insight regarding the benefits of a scenario-based questionnaire compared to a standard 
questionnaire survey, namely: the concepts incorporated in a scenario-based questionnaire can be more meaningful for the respondents. Yang and Gilbert (2008) suggest that one of the differences between qualitative data and quantitative data relates to how meaningful the concepts used are for the real world actors. Concepts used in qualitative data collection are usually more meaningful for real world actors than the concepts used in quantitative data collection, such as in a questionnaire survey. D. T. Robinson, et al. (2007) consider this as one of the disadvantages of the survey as a data collection methodology in ABMS because the respondents' might give responses to concepts that are meaningless for them and hence bias the survey results. In common with a standard questionnaire survey, our base ABMS and scenario-based questionnaire were designed based on the previous literature. However, interviews with the respondents indicate that the use of scenarios can help them to make the concepts used in the modelling more meaningful. In addition, providing open answer options gives the respondents opportunities to express their views on how they make the decisions in reality. As a result, the data from a scenario-based questionnaire, which is designed with sufficient pilot testing, can be more meaningful for the respondents.

The interviewees also found that the scenarios had occurred or were very likely to occur in the real world. Those who ever faced similar situations claimed that their responses to our questionnaire were similar to their actual actions back then. Those who had never faced similar situations claimed that it was very likely that they would take similar actions to their responses in the questionnaire. They also considered this design to more beneficial for them because it stimulated them to think about their action if they were to face a similar real scenario in the future.

The interviewees' responses provide the second insight regarding the usefulness of a scenario-based questionnaire, namely: a scenario-based questionnaire can identify 
how actors react to new scenarios. As mentioned earlier, the data obtained by a standard questionnaire survey are mostly snapshots in time. Consequently, D. T. Robinson, et al. (2007) suggest that the survey method is good for capturing the existing condition but not very suitable for representing temporal variation. Longitudinal surveys are effective in capturing temporal variation but this option can be expensive and is not always feasible within the constraints of a research project. The interviewees reported that the scenarios used in our study could help them to think about the actions they would take in situations they had not yet experienced. This suggests that, though the scenario-based questionnaire survey remains as a snapshot in time, we can still obtain indications of how the real actors will choose their actions in possible future situations. Additionally, these interviews provided an additional form of face-validation that gave us more confidence that the decision rules revealed by the respondents reflected what they actually do.

\subsection{The benefits of a scenario-based questionnaire in improving ABMS validity} The discussion in the previous section shows the benefits of scenario-based questionnaire in eliciting decision rules that can be used in an ABMS model. Another benefit of scenario-based questionnaire is that it allows us to elicit decision rules empirically from the farmers which gives us more confident in the representativeness of the behaviours of agents in our model. This is known as micro-validity (Takadama, Kawai, \& Koyama, 2008).

However, model validation in ABMS needs to be done at least in two levels: micro-validation and macro-validation. Micro-validation evaluates whether the behaviours of individual agents in an ABMS model correspond with the observed behaviours of real-world actors. Macro-validation evaluates whether the behaviours emerging from the interactions between agents in an ABMS model corresponds with the 
observed system level behaviour in the real world. Both micro- and macro-validation are especially important if researchers seek truer representations of human behaviour in studies that uses ABMS (Macal, 2016).

In this section, we investigate whether elicited decision rules can improve the model's macro-validity. The validity concept that we use is operational validity, which considers the match between the ABMS output to the real data (Sargent, 2013). The system-level outputs that we use in macro-validation are cattle population, cow population and milk production as these are considered to be important by both the government and cooperative when recording their statistics (Table 2).

Table 2. Cattle population, cow population and average daily milk production in Pangalengan West Java 2010-2012 (KPBS, 2016).

In Table 3, we compare the macro-validity of the base model (M0) with the empirical models (M1 - M3). The empirical models use one or more elicited decision rules (i.e. buying and selling) obtained from the scenario-based questionnaire. We use the mean error estimation to measure the magnitude of model output deviations from the real data. To estimate the mean error, we measured the difference between model outputs at the end of each simulation year and the real data, from 2010 until 2012 (i.e., Error $_{i}=$ Data $_{i}-$ Simulation $_{i}$ where $i=2010 \ldots$ 2012). We then computed the mean error (ME) from 2011 to 2012 (i.e.ME $=\sum_{2011}^{2012}$ Error $_{i} / 2$ ). Table 3 shows the average $(\overline{M E})$ and standard deviation $\left(S_{M E}\right)$. A t-test was then carried out to infer whether, in the long run, the model's average ME is zero. The two-tailed significance (sig. column) of the $\mathrm{t}$-test at $95 \%$ confidence level is also presented. A lower $|\overline{M E}|$ value indicates that on average the model output is closer to the real data. While, a significance value higher than $5 \%$ indicates that we fail to reject the null hypothesis that the simulation output 
reflects the real-world data (i.e., a valid model). The result shows that the base model is only valid for one output, i.e. cow population. M1-M3 are valid for at least two outputs, indicating models with empirical decision rules are better in terms of improved model macro-validity.

Table 3. The macro-validation of the ABS model.

This finding shows that scenario-based questionnaire can be used to increase the micro and macro validity of our ABS model. Macal (2016) identify model parameterisation (including parameterising the decision rules) and validation based on empirical data as one of the key challenges in ABMS research. Hence, this paper shows that scenario-based questionnaire provides us with a tool to collect empirical data for ABMS model parameterisation and validation.

\subsection{Other benefits and weaknesses of a scenario-based questionnaire}

This section discusses the comparison of our experiences in developing and deploying a scenario-based questionnaire with the views expressed in the previous literature. We consider that there are other benefits of a scenario-based questionnaire, other than those discussed in the two previous sections, namely:

1. A scenario-based questionnaire enables the clarification of the context of the agents' decisions. According to Yang and Gilbert (2008), surveys that are usually used to collect quantitative data place less emphasis on context (i.e., whether and how a decision rule is activated by considering an agent's current state and environment). Furthermore, An (2012) observes that the statistical methods commonly used to analyse survey data are often problematic in providing insight into an agent's motive, incentive and preferences when making a decision. Our experience shows that, with careful pilot testing, it is possible to identify the context of a decision rule using a scenario-based questionnaire. For 
example, we identified that cattle health conditions rather than forage shortage trigger the farmers' selling decision rule. These health condition scenarios were proposed by our pilot testing respondents. By applying statistical analysis to the survey data, we were also able to identify farmers' preferences when selecting the cow to be sold.

2. A variety of established statistical techniques can be used to analyse the data obtained from a scenario-based questionnaire to create decision rules. For example, in our study, the selling decision rule is binary and we used multinomial logistic regression to extract the decision rule and, alternatively, we could use techniques such as curve fitting. It is also possible to incorporate the effect of agent heterogeneity in the decision rule as suggested by D. T. Robinson, et al. (2007). For example, this can be achieved by clustering agents' attributes (e.g., based on demography and socioeconomic parameters, as by Valbuena, et al. (2008)) or by using these attributes as dummy and control variables in a regression model.

Nevertheless, the scenario-based questionnaire in this study also inherits the weaknesses of the survey method. For example, our survey assumes that the head of the farmer household is the sole decision maker in the family (D. T. Robinson, et al., 2007). In reality, each family member may contribute opinions and thoughts when the head of the household make a decision. Also, we rely on statistical techniques to analyse the data and these techniques rely upon many structural and technical assumptions (D. T. Robinson, et al., 2007). Similarly, extrapolation based upon statistical analyses of survey data needs care. Relationships derived from the analyses of survey data can be good at estimating values within the data range (i.e., interpolate). However, when the simulation is running there is potential for the variable values to exceed the range of 
empirical data. In this case, the decision rules derived from the survey are used for extrapolation. When this happens, the decision rule in the ABMS is not representative of the actual agents even if, on aggregate, our simulation result is valid when compared to the real data. We attempted to minimise this potential bias by defining collectively exhaustive parameter ranges to be used during the scenario design process. There were several parameters whose range was a priori unknown (e.g., how long the farmers experience forage shortage before they eventually decide to sell their cows) but, fortunately, these parameters did not significantly affect the farmers' decisions. If these parameters were significant then we could have avoided the potential bias by excluding simulation runs in which these parameters' values exceeded the data range.

\section{Conclusion}

The main contribution of this paper is the detailed discussion of steps to design a scenario-based questionnaire. We have tested the usefulness of scenario-based questionnaires in the case of a dairy supply chain and recorded the respondents' perceptions of the survey. We have shown that the data obtained through the survey is useful for parameterising simulation inputs and improving the micro- and macrovalidity of the ABMS model. Scenario-based questionnaire is particularly useful to elicit behaviours where the respondent's answer corresponds directly with the agent's decision rules in the simulation, for example the smallholder farmers in our case study usually control their own decisions (in contrast to supply chains featuring large organisations in which the decisions are more likely to be made by a management team or via group agreement). Hence, we believe our method can be applied to other study on supply chains with similar characteristics in which ABMS models is used. 


\section{References}

An, L. (2012). Modeling human decisions in coupled human and natural systems: Review of agent-based models. Ecological Modelling, 229, pp. 25-36.

Atzmüller, C., \& Steiner, P. M. (2010). Experimental vignette studies in survey research. Methodology

Axelrod, R. (1997). Advancing the art of simulation in the social sciences Simulating social phenomena (pp. 21-40): Springer.

Azadegan, A., Golara, S., Kach, A., \& Mousavi, N. (2018). Corporate environmental investments: A cross-national study on managerial decision making. International Journal of Production Economics, 199, pp. 47-64.

Bahar, S. (2014). Produktivitas hijauan pakan untuk produksi sapi potong di Sulawesi Selatan. JITV, 19(3)

Bankes, S. C. (2002). Agent-based modeling: A revolution? Proceedings of the National Academy of Sciences, 99(suppl 3), pp. 7199-7200.

Barlas, P., Heavey, C., \& Dagkakis, G. (2015). An open source tool for automated input data in simulation. International Journal of Simulation Modelling (IJSIMM), 14(4)

Boone, R. B., Galvin, K. A., BurnSilver, S. B., Thornton, P. K., Ojima, D. S., \& Jawson, J. R. (2011). Using coupled simulation models to link pastoral decision making and ecosystem services. Ecology and society, 16(2)

Bravo, G. (2011). Agents' beliefs and the evolution of institutions for common-pool resource management. Rationality and Society, 23(1), pp. 117-152.

Bruch, E., \& Atwell, J. (2015). Agent-based models in empirical social research. Sociological methods \& research, 44(2), pp. 186-221.

Choo, A. S., Nag, R., \& Xia, Y. (2015). The role of executive problem solving in knowledge accumulation and manufacturing improvements. Journal of operations management, 36, pp. 63-74.

Cowlrick, I., Hedner, T., Wolf, R., Olausson, M., \& Klofsten, M. (2011). Decisionmaking in the pharmaceutical industry: analysis of entrepreneurial risk and attitude using uncertain information. $R \& D$ Management, 41(4), pp. 321-336.

Eldabi, T., Irani, Z., Paul, R. J., \& Love, P. E. (2002). Quantitative and qualitative decision-making methods in simulation modelling. Management Decision, 40(1), pp. 64-73.

. Encyclopedia of Survey Research Methods. (2008). In P. J. Lavrakas (Ed.), Encyclopedia of Survey Research Methods. Thousand Oaks, California: SAGE Publishing.

Epstein, J. M. (1999). Agent-based computational models and generative social science. Complexity, 4(5), pp. 41-60.

Gilbert, N. (2004). Agent-based social simulation: dealing with complexity. The Complex Systems Network of Excellence, 9(25), pp. 1-14.

Glock, C. H. (2012). Coordination of a production network with a single buyer and multiple vendors. International Journal of Production Economics, 135(2), pp. 771-780.

Glover, J. L., Champion, D., Daniels, K. J., \& Dainty, A. J. (2014). An Institutional Theory perspective on sustainable practices across the dairy supply chain. International Journal of Production Economics, 152, pp. 102-111.

Gross, J., McAllister, R. R., Abel, N., Smith, D. S., \& Maru, Y. (2006). Australian rangelands as complex adaptive systems: a conceptual model and preliminary results. Environmental Modelling \& Software, 21(9), pp. 1264-1272. 
Hahn, H. A. (2013). The conundrum of verification and validation of social sciencebased models. Procedia Computer Science, 16, pp. 878-887.

Happe, K., Hutchings, N., Dalgaard, T., \& Kellerman, K. (2011). Modelling the interactions between regional farming structure, nitrogen losses and environmental regulation. Agricultural Systems, 104(3), pp. 281-291.

Happe, K., Schnicke, H., Sahrbacher, C., \& Kellermann, K. (2009). Will they stay or will they go? Simulating the dynamics of single-holder farms in a dualistic farm structure in Slovakia. Canadian Journal of Agricultural Economics/Revue canadienne d'agroeconomie, 57(4), pp. 497-511.

Heath, B., Hill, R., \& Ciarallo, F. (2009). A survey of agent-based modeling practices (January 1998 to July 2008). Journal of Artificial Societies and Social Simulation, 12(4), p 9.

IAARD. (2012). Kebijakan pencapaian swasembada dan swasembada berkelanjutan lima komoditas utama pertanian melalui pendekatan sistem dinamik Jakarta Selatan: Indonesian Agency for Agricultural Research and Development.

Jafarkarimi, H., Saadatdoost, R., Sim, A. T. H., \& Hee, J. M. (2016). Behavioral intention in social networking sites ethical dilemmas: An extended model based on theory of planned behavior. Computers in Human Behavior, 62, pp. 545-561.

Jager, W., \& Janssen, M. (2002). The need for and development of behaviourally realistic agents. International Workshop on Multi-Agent Systems and AgentBased Simulation.

Janssen, M., \& Ostrom, E. (2006). Empirically based, agent-based models. Ecology and society, $11(2)$

KPBS. (2016). Data Populasi dan Penghasilan Anggota KPBS [Data set]. Retrieved

Lie, H., \& Rich, K. (2016). Modeling dynamic processes in smallholder dairy value chains in Nicaragua: a system dynamics approach.

Lie, H., Rich, K. M., \& Burkart, S. (2017). Participatory system dynamics modelling for dairy value chain development in Nicaragua. Development in Practice, 27(6), pp. 785-800.

Lohfeld, L., Goldie, J., Schwartz, L., Eva, K., Cotton, P., Morrison, J., . . Wood, T. (2012). Testing the validity of a scenario-based questionnaire to assess the ethical sensitivity of undergraduate medical students. Medical teacher, 34(8), pp. 635-642.

Macal, C. M. (2016). Everything you need to know about agent-based modelling and simulation. Journal of Simulation, 10(2), pp. 144-156.

Manish, S., \& Sanjay, J. (2013). Agri-fresh produce supply chain management: a stateof-the-art literature review. International Journal of Operations \& Production Management, 33(2), pp. 114-158.

Mantel, S. P., Tatikonda, M. V., \& Liao, Y. (2006). A behavioral study of supply manager decision-making: Factors influencing make versus buy evaluation. Journal of operations management, 24(6), pp. 822-838.

Marohn, C., Schreinemachers, P., Quang, D. V., Berger, T., Siripalangkanont, P., Nguyen, T. T., \& Cadisch, G. (2013). A software coupling approach to assess low-cost soil conservation strategies for highland agriculture in Vietnam. Environmental Modelling \& Software, 45, pp. 116-128.

Martin, R., Linstädter, A., Frank, K., \& Müller, B. (2016). Livelihood security in face of drought-assessing the vulnerability of pastoral households. Environmental Modelling \& Software, 75, pp. 414-423.

Morano, R. S., de Moraes, E. A., \& Jacomossi, R. R. (2018). Can small groups avoid the tragedy of the commons? AI \& SOCIETY, 33(1), pp. 71-80. 
Morgan, F., Brown, P., \& Daigneault, A. (2015). Simulation vs. definition: Differing approaches to setting probabilities for agent behaviour. Land, 4(4), pp. 914-937.

Moss, S. (2008). Alternative approaches to the empirical validation of agent-based models. Journal of Artificial Societies and Social Simulation, 11(1), p 5.

Nicholson, C. F., Thornton, P. K., \& Muinga, R. W. (2004). Household-level Impacts of Dairy Cow Ownership in Coastal Kenya. Journal of Agricultural Economics, 55(2), pp. 175-195.

Onggo, B. S., \& Hill, J. (2014). Data identification and data collection methods in simulation: a case study at ORH Ltd. Journal of Simulation, 8(3), pp. 195-205.

Onggo, B. S., Hill, J., \& Brooks, R. J. (2013). A pilot survey on data identification and collection in simulation projects. European Simulation and Modeling Conference.

Perera, T., \& Liyanage, K. (2000). Methodology for rapid identification and collection of input data in the simulation of manufacturing systems. Simulation Practice and Theory, 7(7), pp. 645-656.

Quang, D. V., Schreinemachers, P., \& Berger, T. (2014). Ex-ante assessment of soil conservation methods in the uplands of Vietnam: An agent-based modeling approach. Agricultural Systems, 123, pp. 108-119.

Rasch, S., Heckelei, T., Oomen, R., \& Naumann, C. (2016). Cooperation and collapse in a communal livestock production SES model-a case from South Africa. Environmental Modelling \& Software, 75, pp. 402-413.

Rasch, S., Heckelei, T., Storm, H., Oomen, R., \& Naumann, C. (2017). Multi-scale resilience of a communal rangeland system in South Africa. Ecological Economics, 131, pp. 129-138.

Robinson, D. T., Brown, D. G., Parker, D. C., Schreinemachers, P., Janssen, M. A., Huigen, M., . . Irwin, E. (2007). Comparison of empirical methods for building agent-based models in land use science. Journal of Land Use Science, 2(1), pp. 31-55.

Robinson, S. (2004). Simulation: the practice of model development and use: Wiley Chichester.

Sargent, R. G. (2013). Verification and validation of simulation models. Journal of Simulation, 7(1), pp. 12-24.

Schutte, S. (2010). Optimization and falsification in empirical agent-based models. Journal of Artificial Societies and Social Simulation, 13(1)

Skoogh, A., \& Johansson, B. (2008). A methodology for input data management in discrete event simulation projects. 2008 Winter Simulation Conference.

Smajgl, A., Brown, D. G., Valbuena, D., \& Huigen, M. G. (2011). Empirical characterisation of agent behaviours in socio-ecological systems. Environmental Modelling \& Software, 26(7), pp. 837-844.

Su, H.-C., Chen, Y.-S., \& Ro, Y. K. (2017). Perception differences between buyer and supplier: the effect of agent negotiation styles. International Journal of Production Research, 55(20), pp. 6067-6083.

Sunitiyoso, Y., Wicaksono, A., Utomo, D. S., Putro, U. S., \& Mangkusubroto, K. (2012). Developing strategic initiatives through Triple Helix interactions: Systems modelling for policy development. Procedia-Social and Behavioral Sciences, 52, pp. 140-149.

Takadama, K., Kawai, T., \& Koyama, Y. (2008). Micro-and macro-level validation in agent-based simulation: reproduction of human-like behaviors and thinking in a sequential bargaining game. Journal of Artificial Societies and Social Simulation, 11(2), p 9. 
Trybula, W. (1994). Building simulation models without data. Proceedings of IEEE International Conference on Systems, Man and Cybernetics.

Urda, J., \& Loch, C. H. (2013). Social preferences and emotions as regulators of behavior in processes. Journal of operations management, 31(1-2), pp. 6-23.

Utomo, D. S., Onggo, B. S., \& Eldridge, S. (2018). Applications of agent-based modelling and simulation in the agri-food supply chains. European Journal of Operational Research, 269(3), pp. 794-805.

Valbuena, D., Verburg, P. H., \& Bregt, A. K. (2008). A method to define a typology for agent-based analysis in regional land-use research. Agriculture, Ecosystems \& Environment, 128(1-2), pp. 27-36.

Yang, L., \& Gilbert, N. (2008). Getting away from numbers: Using qualitative observation for agent-based modeling. Advances in complex systems, 11(02), pp. 175-185. 


\section{APPENDIX: Scenario-Based Questionnaire}

\section{Scenario 1: These scenarios are used to validate and calibrate buying decision}

rules

Scenario 1a: In the current condition in which you can collect forage (respondent's answer to Part 1) and milk price of (respondent's answer to Part 1), how many more cows do you want to buy, suppose you have enough money to buy the cows and to increase your pen capacity?

Scenario 1b: Please imagine a condition in which the forage availability has increased drastically. With the same amount of labour and time, you can collect twice as much forage as the forage you can collect at this time. However, the milk price you receive stays the same. If you have enough money to buy new cows and to increase your pen capacity, then how many new cows do you want to buy?

Scenario 1c: Suppose the forage availability stays the same but the milk price is double. If you have enough money to buy new cows and to increase your pen capacity, then how many new cows do you want to buy?

Scenario 1d: Please imagine a condition in which the forage availability has increased drastically. With the same amount of labour and time, you can collect twice as much forage as the forage you can collect at this time. In addition, the milk price is also double. If you have enough money to buy new cows and to increase your pen capacity, then how many new cows do you want to buy?

\section{Scenario 2: These scenarios are used to validate and calibrate selling decision rules}

Please imagine that you only have one cow. Unfortunately, you are facing drought in the last 7 days and during this period you can only satisfy $75 \%$ of the forage needed by your cow. When the veterinarian come for his regular visit, he tells you that there is 
$25 \%$ chance of your cow will be sick and die tomorrow. Soon after the veterinarian leaves, you receive a call from a butcher, offering to buy your cow for 15 million. This price is acceptable considering your cow live weight. If you accept the butcher's offer while the veterinarian's prediction does not happen then you lose your potential future income. On the other hand, if you decline this offer and the veterinarian's prediction happen then you will not get anything. In this condition which action will you take?

(a) To sell your cow; (b) to retain your cow; (c) Other, please explain

Notes: For each respondent, we ask several sub-scenarios by varying the drought period, forage sufficiency and cow mortality. The drought period variation is 7 days, 1 month, and 2 months. The forage sufficiency variation is $0 \%, 50 \%$ and $75 \%$. The probability to die variation is $0 \%, 25 \%, 50 \%$ and $75 \%$. If it is difficult for the respondent to imagine probability using percentage, then the information is rephrase using odds (e.g., in one occasion your cow will die and in 3 occasions your cow can survive).

\section{Scenario 3: These scenarios are used to validate and calibrate cow selection}

\section{decision rule}

Please imagine that you have only two cows. You are currently experiencing financial difficulties and are unable to get help, hence you need to sell one of your cows. The money from selling one of these cows can meet your current needs. The first cow is young, currently, it is not pregnant but it can get pregnant easily when given artificial insemination. Your second cow is old, from your record it is hard to get pregnant when it is artificially inseminated, but currently it is pregnant. Which cow do you prefer to sell? 
Figure 1. Flowchart of the base ABMS accompanied with the main literature used to develop each module

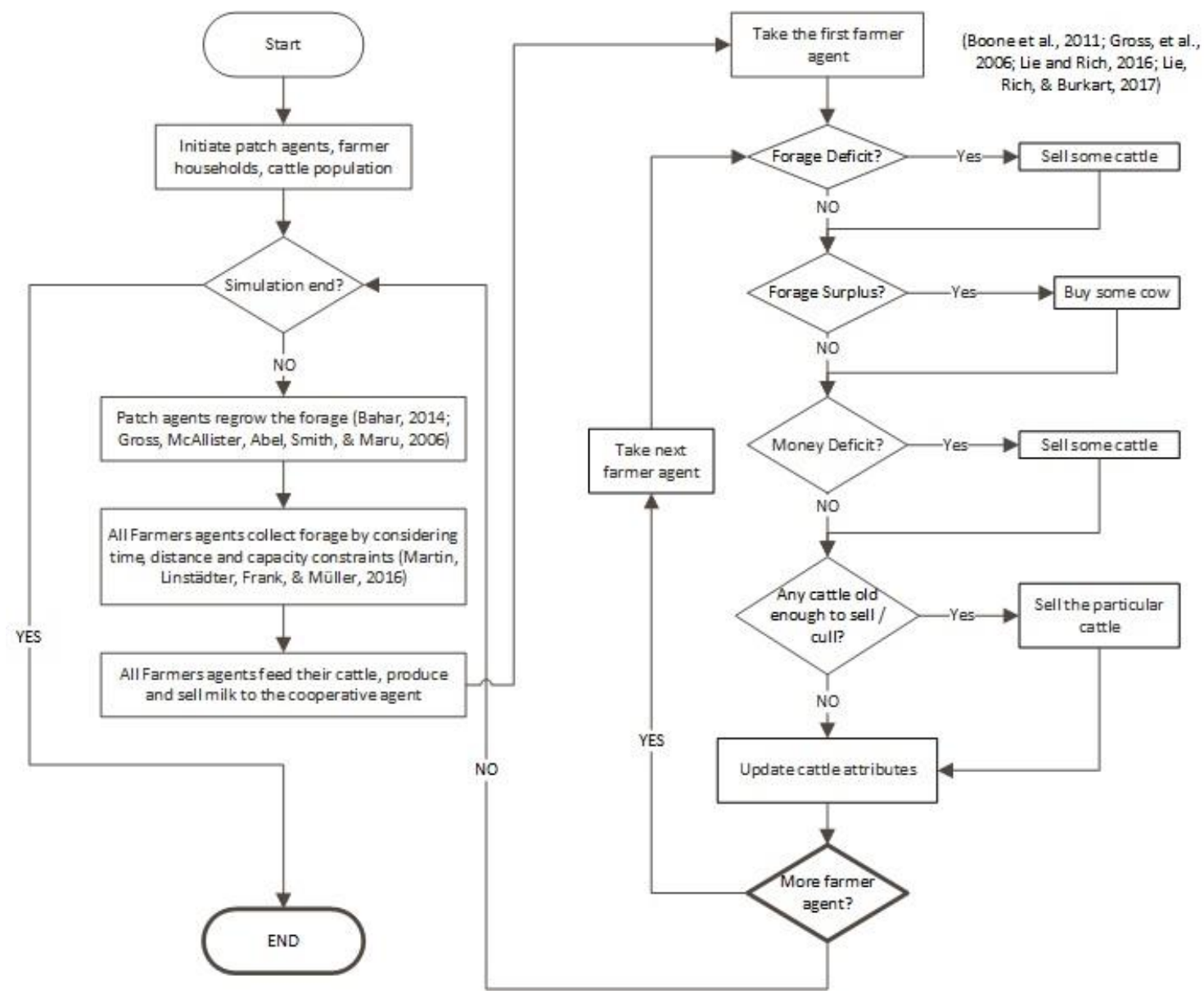


Figure 2. Flow chart of the process to develop survey instrument

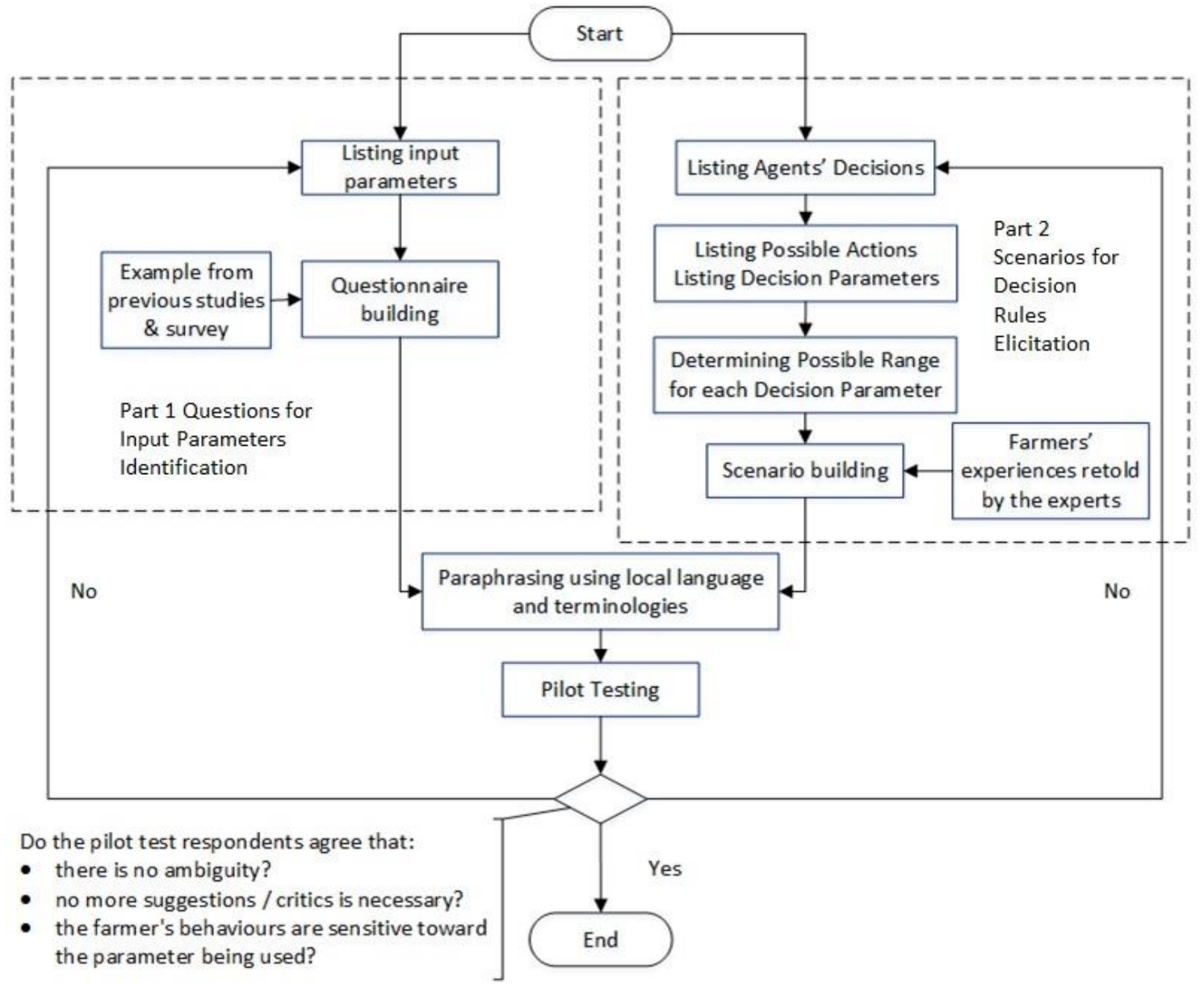


Figure 3. Buying decision rule

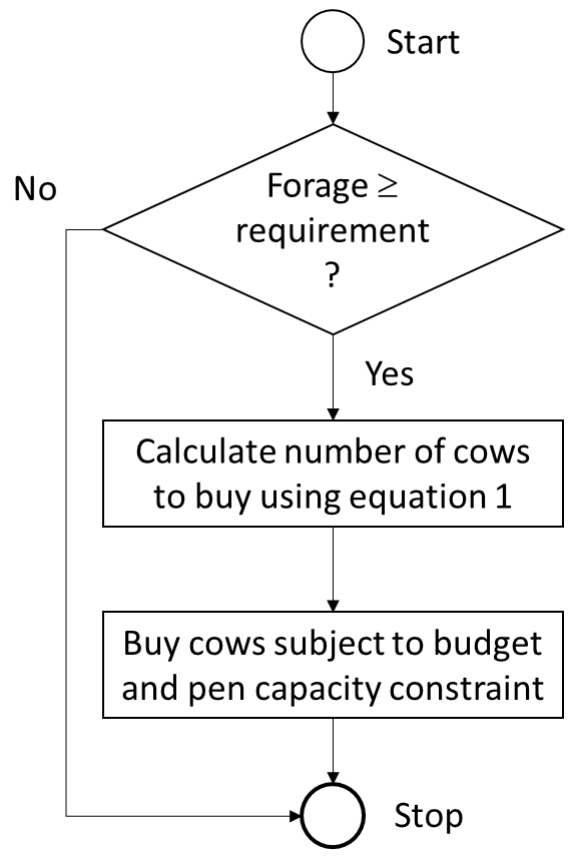

Figure 4. Selling decision rules
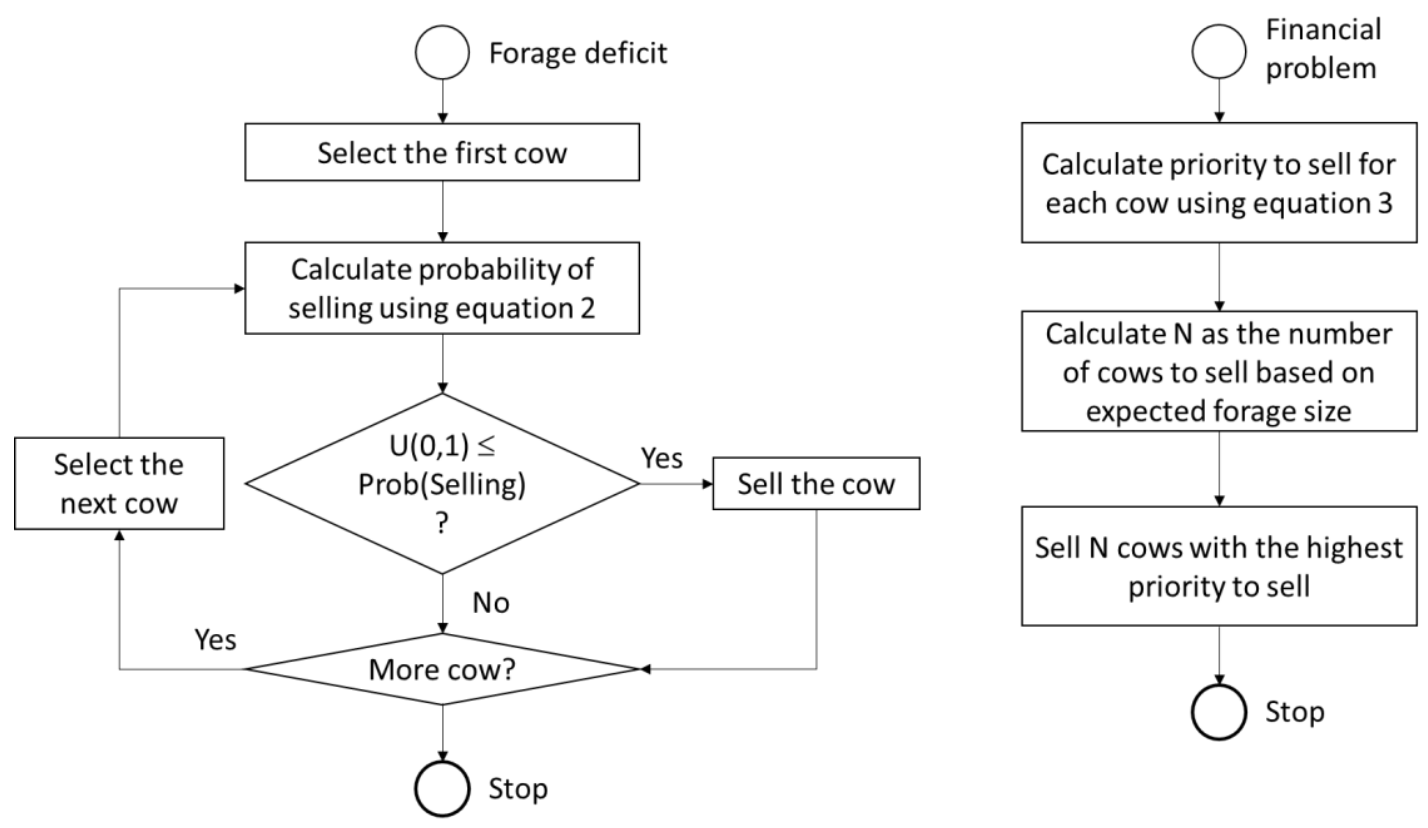
Table 1. Simulation model parameters.

\begin{tabular}{|c|c|c|c|c|c|c|}
\hline \multirow[t]{2}{*}{ Variable Name } & \multicolumn{5}{|c|}{ Descriptive statistics } & \multirow[t]{2}{*}{ Distribution } \\
\hline & Min & Max & Mode & Mean & $\begin{array}{l}\text { Std. } \\
\text { Dev }\end{array}$ & \\
\hline \multicolumn{7}{|l|}{ Agent attributes } \\
\hline Farmer Age (years) & 22 & 74 & 38 & 46.17 & 10.98 & Triangular \\
\hline Family Labour (person) & 0 & 4 & 1 & 0.92 & & Binomial \\
\hline Number of Cow (heads) & 0 & 18 & 3 & 4.10 & & Poisson \\
\hline Number of Bull (heads) & 0 & 5 & 0 & 0.81 & & Poisson \\
\hline Peak Milk Prod (litre) & 10 & 35 & 20 & 20.81 & 19.35 & Normal \\
\hline Service per conception (times) & 1 & 8 & 2 & 2.38 & & Poisson \\
\hline \multicolumn{7}{|l|}{ Constants } \\
\hline Cow Selling Price (millions Rp/head) & & & & 13.1 & & \\
\hline Bull Selling Price (millions Rp/head) & & & & 16.4 & & \\
\hline Heifer Buying Price (millions Rp/head) & & & & 9.6 & & \\
\hline Minimum Milk Price (Rp/litre) & & & & 3,350 & & \\
\hline Maximum Milk Price (Rp/litre) & & & & 5,200 & & \\
\hline Additional Fodder Price (Rp/Kg) & & & & 2,400 & & \\
\hline
\end{tabular}

Table 2. Cattle population, cow population and average daily milk production in

Pangalengan West Java 2010-2012 (KPBS, 2016).

\begin{tabular}{|c|c|c|c|}
\hline Year & Cattle population (head) & Cow population (head) & $\begin{array}{c}\text { Average daily } \\
\text { Production (litre) }\end{array}$ \\
\hline 2010 & 21,322 & 21,083 & 159,333 \\
\hline 2011 & 21,438 & 20,960 & 136,694 \\
\hline 2012 & 22,366 & 22,073 & 138,904 \\
\hline
\end{tabular}

Table 3. The macro-validation of the ABS model.

\begin{tabular}{|l|c|c|c|c|c|c|c|c|c|}
\hline & \multicolumn{3}{|c|}{ Cattle Population } & \multicolumn{3}{c|}{ Cow Population } & \multicolumn{3}{c|}{ Daily Milk Production } \\
\hline Model Name & $\overline{\boldsymbol{M E}}$ & $\boldsymbol{S}_{\boldsymbol{M E}}$ & Sig. & $\overline{\boldsymbol{M E}}$ & $\boldsymbol{S}_{\boldsymbol{M E}}$ & Sig. & $\overline{\boldsymbol{M E}}$ & $\boldsymbol{S}_{\boldsymbol{M E}}$ & Sig. \\
\hline M0 Base model & -2272.3 & 4395.4 & 0.02 & -1443.1 & 4025.3 & 0.09 & 20600.2 & 13421.1 & 0.00 \\
\hline $\begin{array}{l}\text { M1 Buying } \\
\text { decision }\end{array}$ & -1494.8 & 5075.0 & 0.15 & -876.3 & 4703.7 & 0.36 & 16811.3 & 15151.1 & 0.00 \\
\hline $\begin{array}{l}\text { M2 Selling } \\
\text { decisions }\end{array}$ & -1472.9 & 5104.2 & 0.16 & -874.6 & 4586.1 & 0.35 & 6359.1 & 18349.6 & 0.10 \\
\hline $\begin{array}{l}\text { M3 Buying \& } \\
\text { Selling decisions }\end{array}$ & -1504.0 & 5116.5 & 0.15 & -904.4 & 4588.1 & 0.33 & 6118.6 & 18383.3 & 0.11 \\
\hline
\end{tabular}

